\title{
Semantic Facts and a Priori Knowledge $e^{1}$
}

\author{
Fredrik Nyseth
}

[This is a pre-copyedited version of an article accepted for publication in Philosophy. The published article (Nyseth, F. (2017). 'Semantic Facts and a Priori Knowledge'. Philosophy 92, pp. 297-304) is available online at: https://doi.org/10.1017/\$0031819116000632.]

\begin{abstract}
This paper is a response to a paper by Marcus Giaquinto in which he argues that lexical meaning is moderately indeterminate and that this poses a problem for the linguistic view of a priori knowledge. I argue that accepting the moderate indeterminacy thesis as he presents it is perfectly compatible with both the linguistic view in general and the specific suggestion that some a priori knowledge can be explained by appealing to synonymy. I also argue that, in fact, Giaquinto's considerations speak in favour of the linguistic view rather than against it. The general lesson is that, contrary to what might be suspected, the linguistic view does not presuppose an implausibly simple and tidy conception of lexical meaning.
\end{abstract}

\section{Introduction}

One prominent strategy for answering the question ‘how is a priori knowledge possible?' has been to appeal to knowledge of language and meaning. ${ }^{2}$ In particular, it has been suggested that knowledge of some a priori truths - that all bachelors are unmarried being the standard example can be explained (partly at least), by appealing to knowledge of synonymies.

In 'The Linguistic View of a Priori Knowledge', ${ }^{3}$ Marcus Giaquinto argues that this idea is untenable because, although meanings are not as indeterminate as Quine thought, ${ }^{4}$ ' $[\ldots]$ there is enough indeterminacy of lexical meaning for ordinary statements of synonymy to fall short of facthood $[\ldots]$, ${ }^{5}$ If, now, there are no facts about synonymies, there can be no a priori knowledge based on knowledge of such facts either.

\footnotetext{
${ }^{1}$ I am grateful to Tim Button and Luke Cash for helpful comments on an earlier version of this paper.

2 This view has a long history. It has roots in the writings of Hobbes (cf. De Corpore, part I, chapter 3, section 9), had its heyday in the era of logical positivism (cf. e.g. A. J. Ayer, Language, Truth and Logic (London: Gollancz, 1936), ch. 4, and Rudolf Carnap, Meaning and Necessity (Chicago: The University of Chicago Press, 1947), \$2) and has a contemporary defender in Paul Boghossian (cf. 'Analyticity Reconsidered', Nô̂s 30 (1996), 360-391).

${ }^{3}$ Marcus Giaquinto, 'The Linguistic View of a Priori Knowledge', Philosophy 83 (2008), 89-111

${ }^{4}$ W.V. Quine, Word and Object (Cambridge, Mass: MIT Press, 1960), ch. 2.

${ }^{5}$ Op. cit. note 3, 91.
} 
Giaquinto provides plenty of evidence in favour of his thesis of 'moderate indeterminacy of meaning'. I shall not contest this evidence, but I shall contest the conclusion Giaquinto draws regarding the linguistic view of a priori knowledge. As I see it, the moderate indeterminacy thesis does not pose a problem for this view. Indeed, once the dialectical situation is made explicit, we can see that, if anything, Giaquinto's considerations speak in favour of it.

\section{Synonymy and a Priori Knowledge}

The linguistic view, as Giaquinto understands it, holds that one route to a priori knowledge is to deduce it from synonymies and logical truths that are independently known to be a priori. Here is one example he considers (I will refer to this general scheme as 'the synonymy model'):
1) All cows are cows.
(a priori logical knowledge)
2) 'Cow' means the same as 'female bovine'.
(a priori semantic knowledge)
C) So, all cows are female bovines.
(new a priori knowledge)

The idea is that this explains how we can know a priori that every cow is a female bovine (given that we already have some a priori knowledge). As Giaquinto is quick to point out, ${ }^{6}$ there are a number of potential issues with such explanations: First, he says, we may doubt whether the logical truth is available a priori. ${ }^{7}$ Second, we may doubt whether the relevant semantic knowledge is available a priori. ${ }^{8}$ And third, we might worry that claims of the form ' $\mathrm{X}$ means the same as $\mathrm{Y}$ ' are typically not strictly true because there is no fact of the matter. ${ }^{9}$

Giaquinto discusses the first of these worries in the second part of his paper (which I shall not consider here), and is willing to disregard the second for the sake of argument. His objection in the first part of the paper concerns the third worry.

\section{Giaquinto's Objection}

In order for synonymy-based explanations of a priori knowledge to work, there must be semantic facts underlying claims such as (2). Giaquinto claims, however, that if we reflect upon certain

\footnotetext{
${ }^{6}$ Op. cit. note $3,90$.

7 If the linguistic view is to be an explanation of a priori knowledge in general, it is not enough to show that logic is knowable a priori; it must also be shown that the a priori status of logic can be explained in a way that is consistent with the tenet of the linguistic view.

${ }^{8}$ It is often pointed out that this is implausible in the case of public languages. It is less clear what to say if we are dealing with idiolects, as for instance Boghossian does (cf. e.g. note 2 in: Paul Boghossian, 'Inferentialism and the Epistemology of Logic: Reflections on Casalegno and Williamson', Dialectica, vol. 66, no. 2 (2012), 221-236).

${ }^{9}$ A fourth worry concerns the inference itself: Is it valid? Can this be known a prior? And if so, can this knowledge be explained by the linguistic view?
} 
questions about how to individuate meanings, we shall have to conclude that this requirement is typically not met, and that it is simply indeterminate whether two expressions are synonymous.

To substantiate this, Giaquinto considers the question: Does 'cow' (in English) mean the same as 'vache' (in French)? Well, we first observe that 'cow' is used in certain ways that differ from how 'vache' is used. For instance, 'cow' is applied to female elephants and whales, whereas 'vache' is not. ${ }^{10}$ This by itself, though, does not establish that the synonymy doesn't hold, for we might well say that 'cow' is used in several (somewhat similar) senses in English, but that one of these is synonymous with the French word 'vache'. What this response makes clear, however, is that:

[...] the question whether the noun 'cow' has a meaning with respect to which it is synonymous with the noun 'vache' depends on a further question: Does the noun 'cow' have one meaning covering several kinds (female bovines, female elephants, female whales etc.), or two or more related meanings with disjoint extensions, one of which covers just female bovines? ${ }^{11}$

Giaquinto considers several ways of tackling this question, but argues that neither lexicography ${ }^{12}$ nor cognitive semantics ${ }^{13}$ provides any reason to think that there is a determinate answer here.

Though the problem is initially presented in terms of synonymy across languages, this is not essential. In particular, the same worries arise if we replace the French 'vache' with the English 'female bovine', and if so, premise (2) above is in trouble. Of course, if this phenomenon were peculiar to the word 'cow' and perhaps a few others, then it wouldn't be all that significant, but Giaquinto argues that the issue will affect most other - but perhaps not all - cases of (purported) synonymy, including that favourite example: 'bachelor' /'unmarried man'. ${ }^{14}$ The upshot is that it is rarely going to be unproblematically true that one expression is synonymous with another, and so synonymy-based explanations are rarely going to be available.

\section{Is Moderate Indeterminacy a Problem for the Linguistic View?}

I shall not contest Giaquinto's reasons for thinking that moderate indeterminacy of meaning is a widespread phenomenon. My point concerns, rather, what we should conclude if Giaquinto's claims about this are correct. He thinks it shows that there is something wrong with the linguistic view of a priori knowledge:

\footnotetext{
10 Op. cit. note 3, 92.

11 Op. cit. note 3, 92.

12 Op. cit. note 3, 92-93.

13 Op. cit. note 3, 93-96.

14 Op. cit. note 3, 97-98.
} 
The general point is this. For the linguistic story to work at all, words must have determinate meanings and speakers must know just what those meanings are. In many examples this double requirement is not satisfied. ${ }^{15}$

But at this point we should ask: 'examples of what, exactly?' Surely, if this is to be an effective objection against the linguistic view - which is, after all, a claim about how to explain the a prioriwe must be dealing with examples of a priori knowledge. The problem, however, is that insofar as Giaquinto is right about the cases he considers, these aren't examples of a priori knowledge after all.

Take the claim that all cows are female bovines. That might indeed seem like a candidate for a priori knowledge. But if Giaquinto is right, and it is indeterminate whether 'cow', as it occurs in the above claim, can be correctly applied to female elephants, then it is equally indeterminate whether all cows are female bovines. Since we can only know what is true, that disqualifies this from being an instance of a priori knowledge. Similarly for the other cases Giaquinto considers: If the meanings are indeterminate in the way he suggests, the appropriate lesson appears to be, not that these are counterexamples to the linguistic view, but that these aren't candidates for a priori knowledge in the first place. What we need is a case of genuine a priori knowledge that cannot be explained via the linguistic route due to semantic indeterminacy, but no such case is presented. ${ }^{16}$

It is worth noting that Giaquinto is not arguing against the very possibility of a priori knowledge:

\footnotetext{
The problems facing any attempt to devise a satisfactory epistemology of a priori knowledge are substantial. Recognising the difficulties, one might suspect that no epistemology of a priori knowledge is possible, or even that there is no a priori knowledge. But we do not have good grounds for these despairing claims. ${ }^{17}$
}

The thesis of moderate indeterminacy, then, only suggests that there is less a priori knowledge that we might initially have thought; it gives us no reason to reject the idea that all the a priori knowledge there is can be explained by appealing to knowledge of semantic facts.

It might be objected here that while the moderate indeterminacy thesis does not tell against the linguistic view in general, it does tell against the more specific idea that there is a subset of $a$ priori knowledge that can be explained in terms of knowledge of synonymies. ${ }^{18}$ That would be true

\footnotetext{
15 Op. cit. note 3, 96.

16 There are famous problem cases for the linguistic view (e.g. colour incompatibility), but this seems to have little to do with semantic indeterminacy.

17 Op. cit. note $3,111$.

${ }^{18} \mathrm{It}$ is rarely suggested that synonymy is the sole basis of a priori knowledge, though Ayer appears to say this at one point (op. cit. note 2,85 ). Note, however, that in the present context this is not an option since the synonymy model presupposes that we already have some a priori knowledge.
} 
if the thesis established that there are no synonymy facts whatsoever, but Giaquinto is explicit that this claim is too strong. There are some synonymy facts, such as when a term is introduced as abbreviating another expression and perhaps a few others, ${ }^{19}$ and in these cases, synonymy-based explanations are not threatened by moderate indeterminacy of meaning.

Giaquinto concludes, therefore, that ' $[. .$.$] a priori knowledge via knowledge of synonymies$ is at best very restricted ${ }^{20}$ However, this assessment is potentially misleading. It makes it sound as if the synonymy model is at fault for being less explanatory than it ought to be - i.e. that there are instances of a priori knowledge which it ought to account for, but cannot. But, again, this has not been established. Giaquinto certainly considers cases where we might initially have thought that we are dealing with a priori knowledge and the synonymy model should be applicable (e.g. 'all bachelors are unmarried men'). As we have seen, however, this assumption must be revisited if it turns out that these cases are lexically indeterminate and so cannot constitute a priori knowledge after all.

The upshot, then, is not that the synonymy model fails to explain something it ought to explain, but that the phenomenon it is supposed to account for is less prevalent than we thought. This can hardly be held against the synonymy model. Analogously, the hypothesis that all men are mortal does not suffer if it turns out that there are fewer men than we initially believed.

I maintain, then, that the thesis of moderate indeterminacy of meaning does not give us reason to reject either of the following:

i) All a priori knowledge can be explained by appealing to knowledge of semantic facts.

ii) All a priori knowledge of a certain kind can be explained by appealing to knowledge of synonymy facts.

\section{The Correlation between a Priori Knowledge and Semantic Facts}

In this section I shall briefly suggest that, if anything, Giaquinto's considerations speak in favour of the linguistic view since they suggest that there is a tight connection between the possibility of a priori knowledge and the presence of semantic facts.

We saw above that moderate indeterminacy does not pose a threat to the linguistic view since it establishes, in any particular case, not just that there is no semantic fact of the matter, but also that we are not dealing with a candidate for a priori knowledge. In these cases, then, it appears that the semantic facts and the possibility of a priori knowledge stand and fall together. That things turn out this way is no accident, and I want to make it clear that the relevant connection is between determinate semantic facts and a priori knowledge specifically, not just knowledge in general.

\footnotetext{
${ }^{19}$ Op. cit. note 3, 100-101.

${ }^{20}$ Op. cit. note $3,101$.
} 
When considering the case of 'all cows are female bovines', I argued that if the semantic facts are indeterminate in the way Giaquinto suggests, then we cannot even know that all cows are female bovines. However, we can easily tweak things so that we could know this, but not know it a priori due to the semantic indeterminacy. If, for example, all species except humans and bovines became extinct, then it would be true and knowable that all cows are female bovines - even if the meaning of 'cow' is indeterminate in the ways Giaquinto suggests. However, given this alleged semantic indeterminacy, this would still not be knowable a priori since, presumably, we would have to ascertain empirically that there are no female whales, elephants etc. What the lack of a semantic fact precludes is therefore not knowledge, but a priori knowledge specifically. Similar considerations apply to the other cases Giaquinto considers.

This suggests a conclusion quite opposed to that drawn by Giaquinto, namely that we can know a priori that all cows are female bovines if and only if there is a relevant semantic fact of the matter. I am certainly not suggesting that this confirms the linguistic view - firstly, because this single case would be weak inductive evidence indeed, but more importantly, because this only suggests a correlation between semantic facts and the possibility of a priori knowledge, and this does not suffice to establish the explanatory relation claimed by advocates of the linguistic view. Nevertheless, if there is such a correlation, this is surely a point in favour of the linguistic view, rather than a point against it.

We should note, finally, that other remarks by Giaquinto provide further evidence for a correlation here. Since he is concerned to argue for a moderate kind of indeterminacy, he is explicit that there are semantic facts:

The kind of indeterminacy proposed here is moderate. There are lexical meaning facts, on the moderate view. For example, the noun 'cow' does have a meaning which allows (i.e. has as one of its possible outputs) its use for female domestic cattle, but does not have a meaning which allows its use for female spiders. ${ }^{21}$

It is a semantic fact, that is, that 'cow' cannot be correctly applied to female spiders. Now, if this is correct (and making the concessions that Giaquinto makes about other problematic aspects concerning the linguistic view), then it would seem that we can know a priori that no cow is a female spider. In general then, reflection on the issue of moderate indeterminacy of meaning suggests that a priori knowledge requires the presence of relevant semantic facts, and that when such semantic facts are present, so is the possibility of a priori knowledge.

\section{Conclusion}

\footnotetext{
21 Op. cit. note 3, 99
} 
I have argued that moderate indeterminacy of meaning does not pose a problem for either the linguistic view of a priori knowledge in general, or the synonymy model specifically. In particular, the thesis does not suggest that linguistic and synonymy-based explanations account for too little of our a priori knowledge, only that there is less a priori knowledge than we might have thought. Giaquinto is incorrect, therefore, when he claims that moderate indeterminacy ' $[. .$.$] undermines$ the idea of a priori knowledge based on knowledge of synonymies. ${ }^{22}$ While he might have established that 'a priori knowledge via knowledge of synonymies is at best very restricted', ${ }^{23}$ he has not given us reason to think that it isn't exactly as restricted as it ought to be.

I have also argued that these considerations suggest a correlation between the availability of semantic facts and the possibility of a priori knowledge, and that this, if anything, is a point in favour of the linguistic view.

Though I have been concerned to reply to Giaquinto's paper specifically, there is a general lesson here. The linguistic view of a priori knowledge is certainly less popular than it used to be, and one reason for this, I suspect, is that it is taken to presuppose an outdated and implausibly simple conception of meaning, according to which meanings are abstract objects with neat, determinate properties. ${ }^{24}$ The linguistic view is therefore regarded as undermined by the fact that matters of meaning are often messy and indeterminate. However, as is argued above, the relevant issue is not the extent to which meaning is indeterminate, but the extent to which meaning is indeterminate relative to the possibility of a priori knowledge - that is, whether there are clear cases of a priori knowledge where the relevant semantic issues are too indeterminate for the linguistic story to work.

\footnotetext{
22 Op. cit. note 3, 89.

23 Op. cit. note 3, 101.

${ }^{24}$ Quine referred to something like this conception as 'the myth of a museum', where '[...] the exhibits are meanings and the words are labels.' (W.V. Quine, 'Ontological Relativity', The Journal of Philosophy, vol. LXV, no. 7 (1968), 185212).
} 